\title{
LA OBRA INMACULISTA DE LOS MORA Y SU CÍRCULO EN EL ARZOBISPADO DE GRANADA
}

Data recepción: 2013/11/10

José Antonio Peinado Guzmán

Data aceptación: 2014/04/01

Universidad de Granada

Contacto autor: pepeinado@hotmail.com

\section{RESUMEN}

La familia de los Mora, a caballo entre el siglo XVII y XVIII, supone un hito dentro de la escuela granadina de escultura. Su ingente producción se concentra principalmente en la temática de Pasión. Este artículo recoge su labor en la iconografía inmaculista, deudora de los cánones de Alonso Cano. El trabajo de taller que comenzará a partir del menor de los Mora, Diego, permitirá que los encargos artísticos se multipliquen. Será a raíz de Diego de Mora cuando contemplemos algún prototipo iconográfico inmaculista diferente del ideado por el racionero Cano. El texto que proponemos aborda la catalogación de los diferentes arquetipos que desarrollan los Mora en la temática concepcionista, además de sacar a la luz algunas imágenes desconocidas que consideramos de su factura.

Palabras clave: José de Mora, Diego de Mora, Granada, Inmaculada Concepción, escultura, taller, iconografía

\begin{abstract}
Operating between the seventeenth and eighteenth centuries, the Mora family represented the apogee of the Granada school of sculpture. Their enormous output centred mainly on the theme of the Passion of Christ. This article looks at the iconography they produced on the theme of the Immaculate Conception, work indebted to the canons of Alonso Cano. The studio work that began with the youngest of the Moras, Diego, led to an increase in the number of artistic commissions, with his output marking a departure in the iconography of the Immaculate Conception from that produced by the prebendary Cano. This paper addresses the cataloguing of the various archetypes developed by the Mora family on the theme of the Immaculate Conception and also reveals some unknown images that we believe to be of interest.
\end{abstract}

Keywords: José de Mora, Diego de Mora, Granada, Immaculate Conception, sculpture, workshop, iconography

La obra escultórica de los Mora en Granada supone uno de los máximos exponentes de la escuela granadina de escultura ${ }^{1}$. Su legado artístico, que abarcaría desde el último tercio del siglo XVII hasta la segunda mitad del XVIII, alcanza el punto más álgido de expresividad minimalista, misticismo, hondura de sentimiento y recogimiento conmovedor en la imaginería granadina. Su escultura, ideada para remover la sensibilidad del fiel que la contempla, se hace sublime en las iconografías de Pasión: Crucificados, Dolorosas, Nazarenos... La saga, que daría comienzo con el padre, Bernardo, tendría su continuidad con el genio magistral de José de Mora. De Bernardo hijo conocemos su magistral obra en la Colegiata de Alcalá La Real (Jaén), destruida en el conflicto bélico de 1936. El menor de la familia, Diego, perpetuaría la labor escultórica en un prolífico taller, en el cual aprenderían el oficio hasta diecinueve discípulos, entre los que se encontrarían, Torcuato Ruiz del Peral, Pedro Tomás Valero, Agustín de Vera Moreno...

Debido a que la producción de esta familia de escultores es tan abundante y variada, nos vamos a centrar en un aspecto de su obra, la iconografía inmaculista y, concretamente, en el entorno granadino. Ésta se inserta en ese proceso de dilucidación de la denominada "cuestión concepcionista" que, a lo largo del siglo XVII, invadió la sociedad española con aquellas disquisiciones teológicas. Cuando Alejandro VII, 
mediante la Bula Sollicitudo omnium ecclesiarum, en 1661 deja aclarada la postura oficial de la Iglesia con respecto a la temática inmaculista, se va a producir un incremento artístico de estos modelos iconográficos para conmemorar tal pronunciamiento papal. Es en este sustrato donde se sitúa la obra concepcionista de los Mora.

La escultura de José de Mora, aunque perteneciente a la escuela granadina y deudora del magisterio de Alonso Cano, no tiene el influjo tan directo como en el caso de Pedro de Mena, por ejemplo. En líneas generales, la gubia de Mora se caracteriza por la exaltación del sentimiento, de la emoción, con cierta dosis de pasión, pero siempre manteniendo en su estilo una sencillez, intimismo y recatamiento considerables. En el caso de la iconografía inmaculista, por su propia idiosincrasia, no se presta a ser representada con excesiva afectividad. La quietud y sosiego que conlleva el modelo requiere contención en las formas. Además de esto, su vinculación al tipo del Racionero en el tema de la Inmaculada, perpetuado, asimismo, en su maestro y pariente Pedro de Mena es palpable. Aun así, tanto en el tratamiento de los paños como en la composición de los ángeles de la peana, se vislumbra un barroquismo que va rayando en lo exacerbado. Este es el caso del ejemplo de la iglesia parroquial de los Santos Justo y Pastor ${ }^{2}$. Esta obra, que se data entre 1671-1674, se ubica en el tabernáculo del presbiterio. De similares trazas, casi miméticas, es también la que se halla en la sacristía de la Catedral de Guadix.

Según esto, el modelo de la antigua iglesia jesuita, lo observamos erguido, sobre una peana en la que se aprecian innumerables angelotes, tanto en cabezas aladas como de cuerpo entero. Entre ellos aparece la serpiente, símbolo del pecado. Curiosamente, un elemento tan característico en la iconografía concepcionista como el lunar, en este ejemplo desaparece. La imagen, muy de corte canesco, une sus manos a la altura del pecho, desplazándolas ligeramente hacia la derecha, tocándose las yemas de los dedos con sutileza. En este sentido, recuerda también la Inmaculada de Alhendín, obra de Pedro de Mena. Su torso se mantiene quieto, contraponiéndose al movimiento de su cabeza, que se gira hacia la derecha levemente. Este detalle de dinamis- mos opuestos, le proporciona a la escultura una movilidad equilibrada, como un movimiento latente. En su rostro y su mirada se reflejan el semblante sereno y reflexivo, que acostumbra la plasmación del Misterio. En su cabello, de parecido modelado a lo acostumbrado en el tipo de Alonso Cano, se percibe mínimamente un mayor volumen en los laterales de la cara (Fig. 1).

La Virgen viste los habituales ropajes inmaculistas. En la túnica blanca se vislumbra el trabajo en estofa, aunque no se aprecian motivos decorativos concretos. Cubriendo la prenda, observamos el clásico manto azul, desarrollando las maneras ahusadas del Racionero. Por el borde del manto, recorre una sencilla cenefa en oro. En lo referente al plisado de los paños, se percibe el trabajo característico de la obra de Mora. Abundan los pliegues menudos, abundantes, cortantes y geométricos. En la parte inferior de la vestidura se contemplan más duros y profundos. La voluminosidad que se pretende dar al manto hace que sus ondulaciones, aun siendo de similares trazas que en la túnica, aparezcan un tanto más suaves y matizadas. El terciado del paño, que deja al descubierto el hombro derecho de la mujer, hace caer un destacado pico sobre el brazo izquierdo, marcando unos pronunciados plisados.

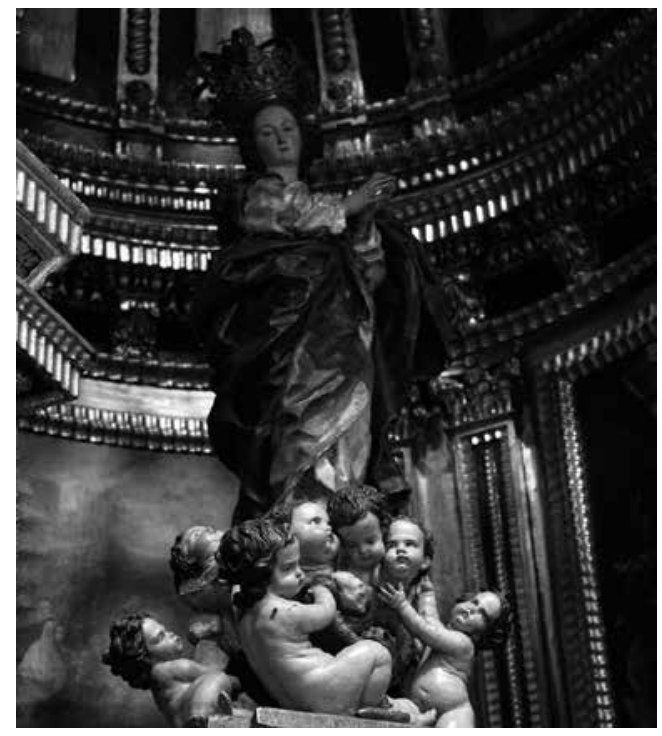

Fig. 1. Inmaculada. Iglesia parroquial de los Santos Justo y Pastor (Granada). José de Mora, 1671-1674. 
Otra muestra que creemos salida del taller de Mora es la talla que encontramos en el templo parroquial de la localidad de Alhama de Granada ${ }^{3}$. De la imagen original, prácticamente destruida en la Guerra Civil, únicamente queda la cabeza de la talla. El cuerpo de la misma fue realizado a mediados del siglo XX (Fig. 2).

El trabajo del menor de los Mora, Diego, es más abundante debido a la ingente labor de taller que realizó. Según esto, un curioso ejemplo de Inmaculada relacionado con la gubia de los Mora, lo encontramos en la parroquial de San José $^{4}$. Aunque la mayoría de autores se inclinan por pensar que su autoría es de Diego, existen también atribuciones a José y a Bernardo. Personalmente, nos decantamos por postular que la imagen pertenecería a la obra de Diego de Mora, pudiéndose realizar en torno a 1685. Llama poderosamente la atención la disposición de la imagen, cercana a modelos castellanos anteriores $\mathrm{o}$ a las primitivas obras inmaculistas de Alonso de Mena, de quien pudo copiar la composición. Curiosamente, en el templo albaicinero, y prácticamente contigua a ésta, hallamos una talla del mencionado Mena, que sigue estos cánones. No quiere decir esto que exista una relación entre ambas imágenes por el hecho de ubicarse en la misma iglesia. La talla perteneció a la antigua cofradía de zapateros de San Crispín y San Crispiniano, que pasó de su originaria parroquia de San Gil a Santa Escolástica, para finalmente, en 1888, terminar en San José. En el inventario de 1867, el párroco de San Gil, Don Félix Gámez, declara que dicha cofradía llevaba en su haber "una Ymagen de la Concepcion de talla y cuerpo de una persona mediana con su corona y media luna de lata, dos angeles tallados en la misma peana". Probablemente, el devenir del tiempo hizo que desaparecieran los dos ángeles de talla. Aun así, en la base de la escultura se pueden apreciar hasta cinco hendiduras donde creemos que estaban ubicados dichos angelotes. Asimismo, sabemos que hasta mediados del siglo XX, la imagen de Mora estuvo ubicada en la capilla de San Nicolás, acompañándose de los mencionados santos Crispín y Crispiniano.

Junto a esto, y salvando las evidentes diferencias, encontramos dos tallas que podemos relacionar con este ejemplo de San José. Una de ellas es la que se guarda en la parroquia de Cogollos Vega ${ }^{5}$ y otra en la de Albolote ${ }^{6}$. En la primera apreciamos una mayor similitud en el rostro y pose con respecto a la del templo albaicinero. La colocación del manto difiere. En cambio, en el ejemplo de Albolote, mantiene un mayor parecido en las vestiduras y posición de la imagen, aunque se distancie notablemente en la fisonomía.

Dicho esto, observamos la escultura de la parroquial de San José según la disposición tradicional, erguida sobre dosel nuboso. En este caso, carece de ángeles, serpiente e incluso de luna tallada. La que presenta es metálica, con las puntas hacia arriba, pero de adición posterior. Une sus manos a la altura del pecho, centradas y tocándose únicamente las yemas de los dedos. La pose triangular e inclinada hacia adelante de las mismas, recuerda nuevamente a los modelos de Alonso de Mena. Su torso carece de movimiento alguno. La cabeza mantiene una posición frontal, ligeramente movida hacia la derecha. El rostro ofrece una reseñable belleza: pe-

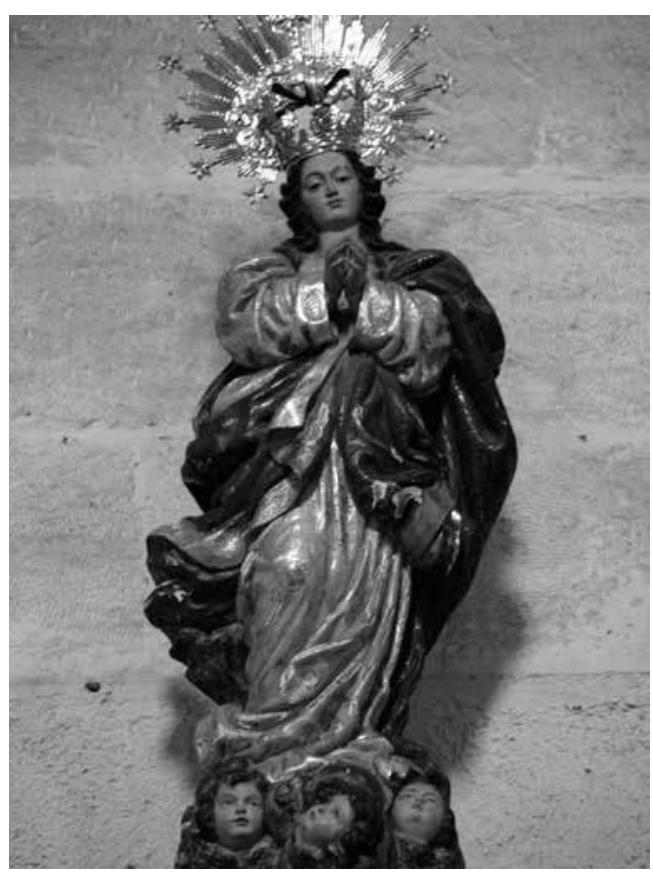

Fig. 2. Inmaculada. Iglesia parroquial de La Encarnación de Alhama de Granada (Granada). Atribuida a José de Mora, finales del siglo XVII o principios del siglo XVIII. 
queña boca, gracioso hoyuelo en la barbilla, nariz recta, ojos almendrados sutilmente inclinados en diagonal, pestañas naturales y destacadas cejas arqueadas. La policromía rosada de su tez, ayuda a enaltecer la hermosura de su cara. Muy lucido y destacado es el trabajo efectuado en el cabello. Considerablemente largo y moreno, la labor de la gubia en los ensortijados mechones, realizados uno a uno, constituye un ejercicio de talla primoroso. Por tanto, podríamos concluir que la imagen perteneciente a la cofradía de zapateros fue realizada por el menor de los Mora, siguiendo criterios estilísticos. Finalmente, orla su testa con corona real, sobre la que se disponen las estrellas habituales.

La Virgen viste túnica blanca, sobre la que aparece una rica decoración con motivos florales y vegetales, en tonos dorados, azules y rojos. Los adornos en oro desarrollan la técnica del picado de lustre. En líneas generales, ese modo de exornar el tejido, a lo chinesco, es muy propio de la centuria del setecientos. Por los bordes del cuello y mangas, se aprecia similar decoración dorada. La vestimenta se ciñe en talle alto mediante cíngulo rojo. Presenta bocamangas en color blanco. Cubre sus espaldas con manto azul, no dispuesto según el terciado ahusado del tipo canesco, y con un curioso recogido en la trasera. La prenda se abre a ambos lados, proporcionándole a la escultura un aspecto triangular acuciado. Recorre el filo del paño, idénticos motivos dorados en picado de lustre. En lo concerniente al plegado de los paños, son más destacados los plisados de la túnica que los del manto. En aquélla se aprecian marcados, abundantes y suaves, dibujando líneas notoriamente verticales, según la caída del tejido. Los pliegues del manto se perciben más convencionales y simples. La apertura del manto ofrece cierto volumen a la prenda. Sus ondulaciones son suaves, presentando dos destacados profundos pliegues en la parte frontal (Fig. 3).

Probablemente, la adhesión al modelo piramidal y macizo de principios del XVII ha inducido a pensar en Bernardo de Mora como autor. Pero debe entenderse esto como una revisión historicista del tipo iconográfico solamente porque en los detalles particulares (plegado, fisonomía y virtuoso tratamiento del cabello), se advierte un concepto dinámico y artificioso más tardío.
El tratamiento de los paños es compatible con el estilo de José de Mora pero la complejidad habilidosa de algunas partes y la fisonomía permiten sostener la atribución a Diego de Mora.

Otra muestra que presentamos relacionada con las gubias de Diego de Mora, es esta talla que se encuentra en la clausura del convento de agustinas recoletas de Santo Tomás de Villanueva ${ }^{7}$. Nuevamente se aleja en esta imagen de los tipos canescos, proponiendo un modelo de acentuado barroquismo al exacerbar el vuelo de los paños, además de presentar una pose diferente a la establecida por el Racionero en su prototipo. Observando la imagen detenidamente, y ante la ausencia de elementos tan característicos de la iconografía concepcionista como la luna o la serpiente-dragón, el amplio desarrollo de las vestimentas nos hace cuestionarnos si nos encontramos ante una imagen de la Inmaculada o de la Asunción. Si seguimos el criterio de Reau, su mirada y semblante bajo, "con los ojos dirigidos hacia la tierra"8, nos indicaría que se trata de una talla inmaculista, en contraposición a las

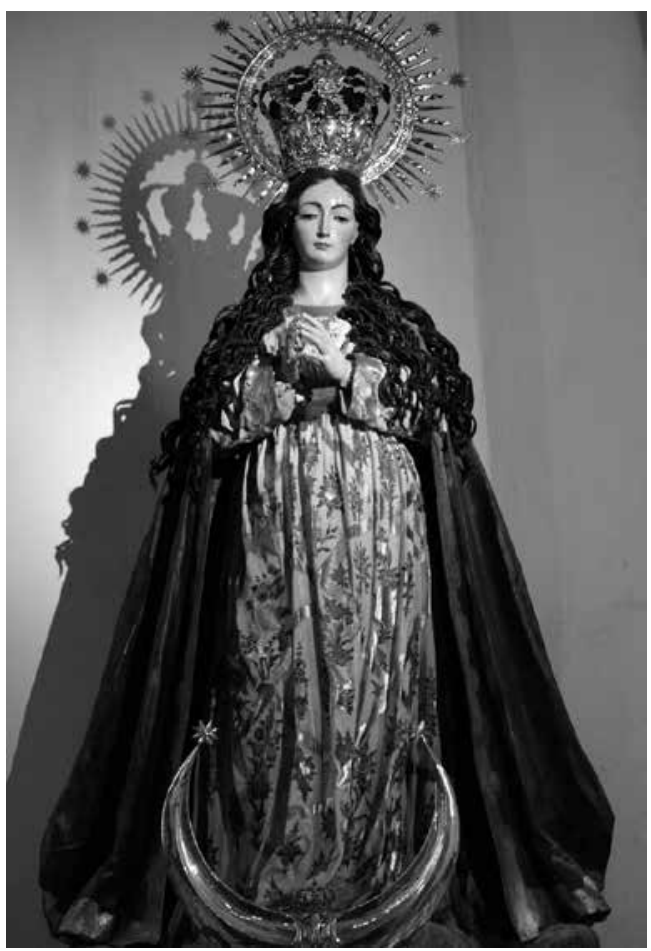

Fig. 3. Inmaculada. Iglesia parroquial de San José (Granada). Diego de Mora, c. 1685. 
imágenes asuncionistas, que tienden a levantar la vista al cielo. Ahora bien, este particular punto de vista no se cumple taxativamente en todos los casos, por lo que no se puede extrapolar a toda la casuística (Figs. 4 y 5).

Según esto, la figura mariana se sitúa en una peana, sobre estrado de nubes y, según lo mencionado anteriormente, carente de los habituales elementos concepcionistas que acompañan la iconografía. La Virgen, erguida, hace amago de adelantar el pie izquierdo, mante-

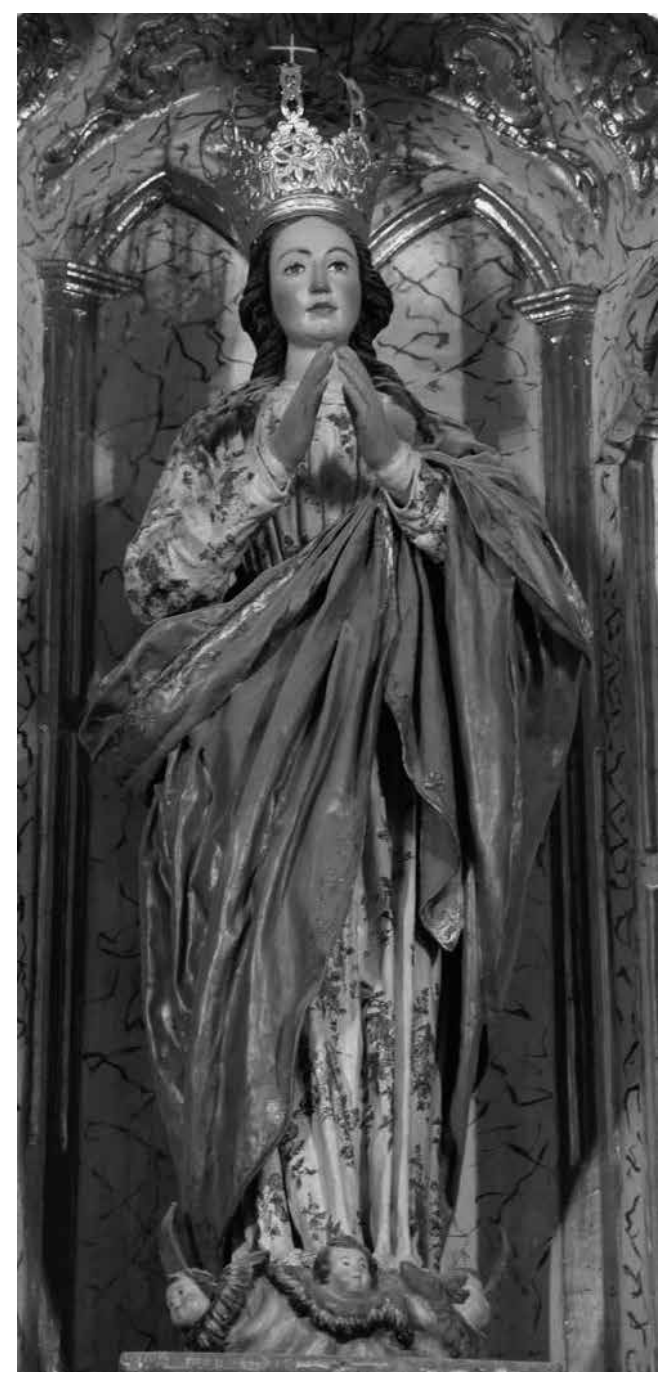

Fig. 4. Inmaculada. Iglesia parroquial de La Anunciación de Cogollos Vega (Granada). Círculo o taller de Diego de Mora, finales del siglo XVII o principios del siglo XVIII. niendo el opuesto en reposo. Su torso desarrolla un acentuado contraposto, al esbozar con todo su cuerpo una marcada línea serpenteante: las extremidades inferiores tienden a moverse hacia la izquierda, cintura y pecho viran a la derecha, mientras que la cabeza, finalmente, se gira nuevamente al lado opuesto. Sus manos, rompiendo el esquema canesco, no se unen. La derecha se dispone sobre el pecho, mientras que la contraria queda al aire delicadamente. En este sentido, parece querer copiar los modelos de la escuela madrileña de pintura, tipo Carreño de Miranda, que suelen utilizar este recurso. También el vuelo agitado del manto a su derecha es de clara fijación pictórica. Esto viene a mostrarnos las mutuas influencias que se dan entre pintura y escultura, y a la inversa. Recordemos que, a principios del siglo XVII, descubrimos el modelo de Pablo de Rojas en muchas pinturas; ahora ocurre al revés. Su rostro, según hemos descrito en ejemplos precedentes de este autor, repite similares trazas: cara ovalada, boca pequeña, nariz recta, hoyuelo en la barbilla, ojos almendrados y cejas arqueadas, además del cabello un poco más vo-

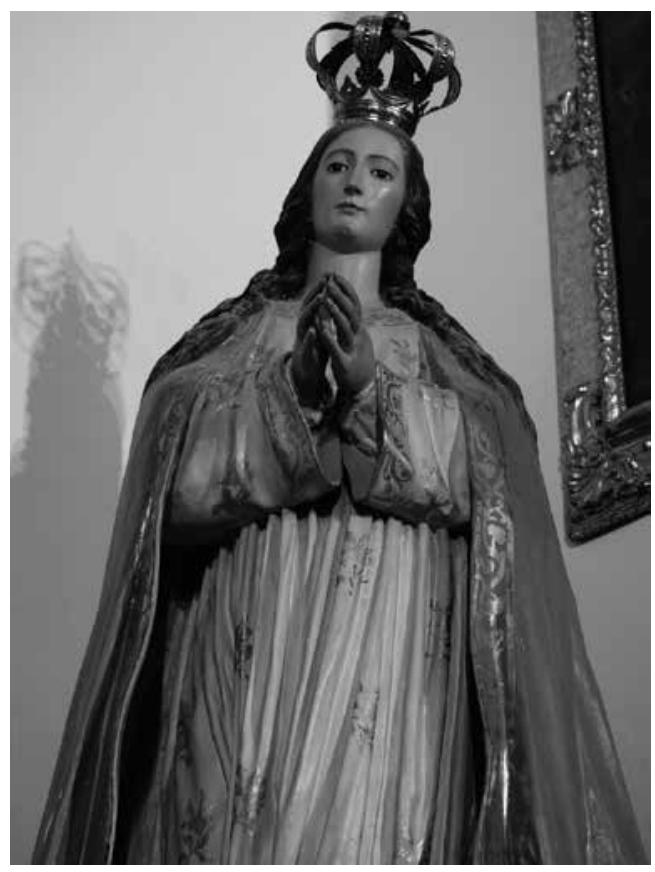

Fig. 5. Inmaculada. Iglesia parroquial de La Encarnación de Albolote (Granada). Círculo o taller de Diego de Mora, finales del siglo XVII o principios del siglo XVIII. 
luminoso a la altura de las mejillas. Adorna su cabeza con corona real en plata (Fig. 6).

La Virgen viste la clásica túnica blanca, de tono crudo, ceñida en talle alto mediante cíngulo rojo. Se decora la prenda con ricos motivos chinescos, de parecido tipo a los que encontramos en la Inmaculada de la parroquia de San José, en coloración rojiza, amarilla y verdosa. Las mangas internas son de tonalidad roja. Cubre sus espaldas el consabido manto de color azul. La disposición del mismo resulta peculiar, puesto que tiene más parecido con una capa. Por el borde de la prenda recorre una bella cenefa en oro, elaborando una lucida decoración vegetal. Asimismo, enriquece el paño un bello encaje dorado que, en algunas zonas, se aprecia bastante deteriorado por el paso del tiempo. En lo referente a los plisados, la túnica sigue el dibujo que genera la movilidad del cuerpo. En este sentido, en la parte inferior de la vestimenta, se perciben pliegues más profundos y suaves, marcando líneas sensiblemente diagonales.

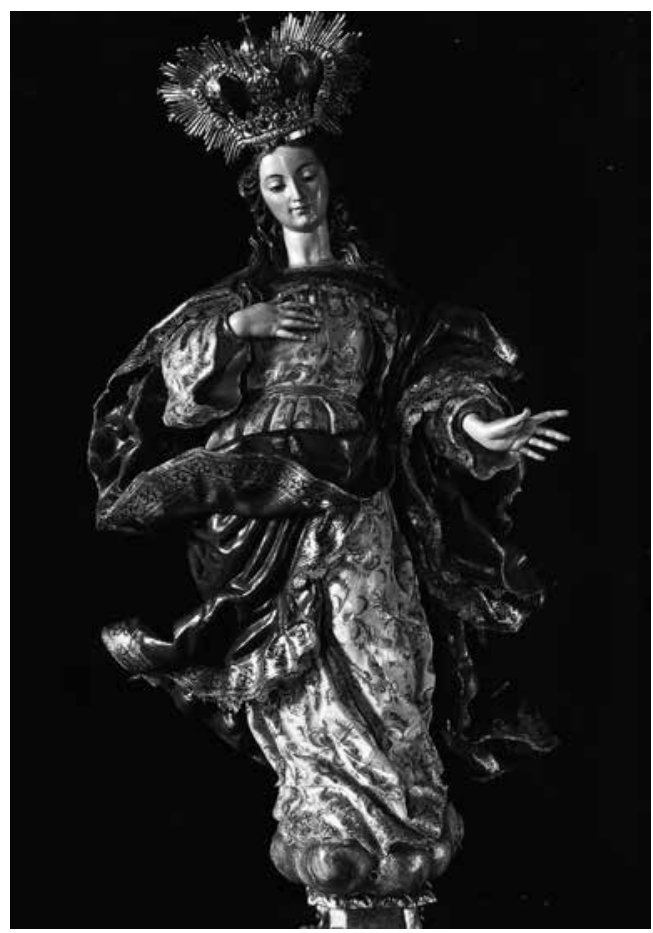

Fig. 6. Inmaculada. Clausura del Convento de Madres Agustinas Recoletas de Santo Tomás de Villanueva (Granada). Atribución a Diego de Mora, finales del siglo XVII o principios del siglo XVIII.
Pero lo más destacado de los tejidos y, por qué no, de la escultura en sí, son los enormes vuelos del manto. Sujeto al cuello, uno de los picos se cruza de izquierda a derecha para terminar cayendo sobre el brazo izquierdo de la Virgen con pomposidad. La grandilocuencia en la volatilidad de la vestidura, provoca que se generen profundas, abundantes y menudas ondulaciones. Éstas, aunque suaves, van trazando líneas en todas direcciones.

Siguiendo este prototipo, encontramos un ejemplo similar en la iglesia parroquial de Nuestra Señora del Rosario de la localidad de Güéjar Sierra9. También del círculo de Diego de Mora, aunque esta vez siguiendo los cánones canescos, sería la Inmaculada de la iglesia parroquial de la Santa Cruz, de la localidad alpujarreña de Pampaneira (Figs. 7 y 8).

Entrando en el terreno de las atribuciones dudosas o que consideramos erróneas, nos encontraremos con dos imágenes concretas: la Virgen de la Buena Dicha y la Inmaculada del facistol de la Catedral granadina.

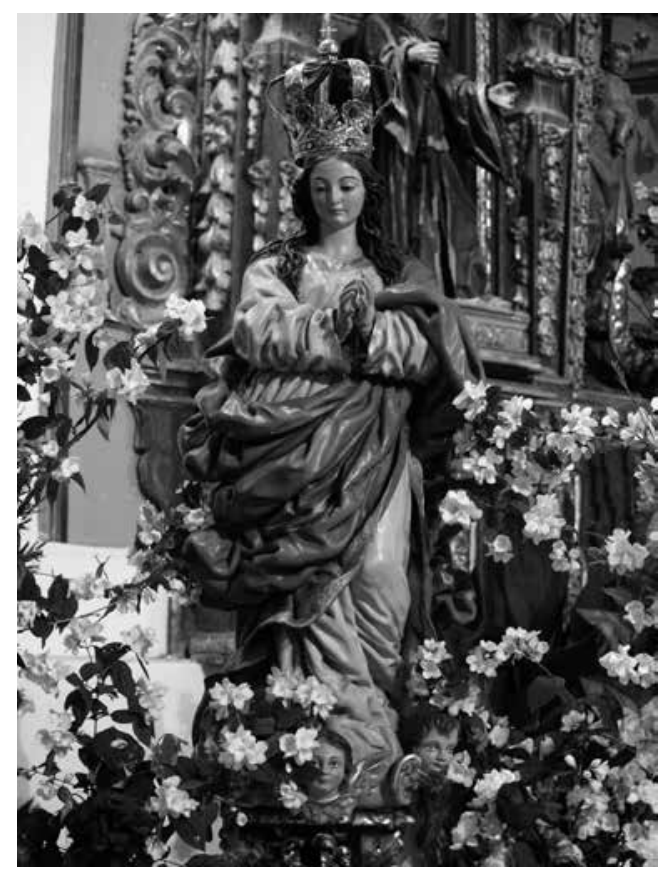

Fig. 7. Inmaculada. Iglesia parroquial de la Santa Cruz de Pampaneira (Granada). Círculo o taller de Diego de Mora, finales del siglo XVII o principios del siglo XVIII. 


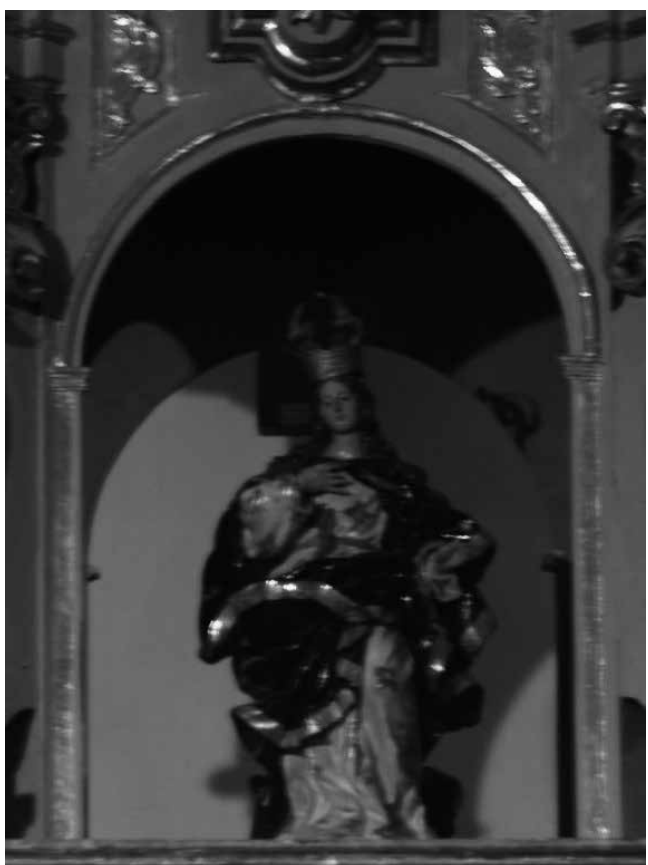

Fig. 8. Inmaculada. Iglesia parroquial de Nuestra Señora del Rosario de Güéjar Sierra (Granada). Círculo o taller de Diego de Mora, finales del siglo XVII o principios del siglo XVIII.

La primera de ellas es una bella imagen de la Inmaculada que se conserva en la iglesia parroquial de San Pedro y San Pablo, talla que tradicionalmente ha presentado numerosas dudas al intentar establecer una autoría determinada ${ }^{10}$. La mayoría de los especialistas se decantan por concedérsela a José de Mora. Tan sólo Gallego y Burín, y no siempre, la ha atribuido a Pedro de Mena ${ }^{11}$. Personalmente, nos decantamos por la opción de José de Mora o, al menos, de su entorno. El trabajo de la gubia recuerda más sus hechuras que a las de Mena, quien tiende a estilizar más los pliegues, esbozándolos de modo más sobrio. No descartamos la posibilidad de que sea una obra primigenia de José, o de su padre Bernardo. Recordemos que éste estaba ya esculpiendo en Granada a finales de la década de los cuarenta del XVII. Aun así, no dejan de ser meras especulaciones. Un dato que decantaría la balanza de la autoría en favor de los Mora en detrimento de Pedro de Mena, sería la fundación en 1690 de la Hermandad de Nuestra Señora de la Buena Dicha. Si la imagen se contrató una vez fundada la cofradía, como la lógica mandaría,

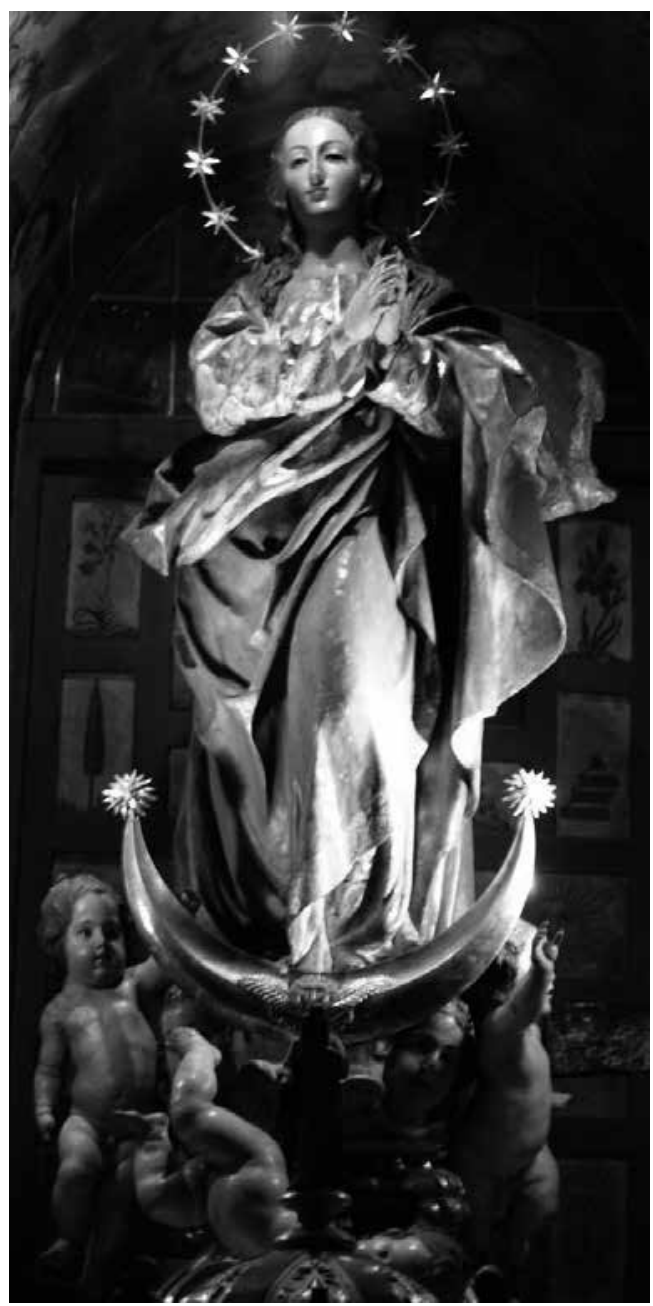

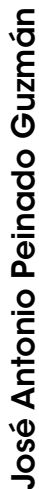

Fig. 9. Inmaculada. Virgen de la Buena Dicha. Iglesia parroquial de San Pedro y San Pablo (Granada). Atribución dudosa a Pedro de Mena o a José de Mora, mediados del siglo XVII.

Mena llevaba ya dos años muerto. Esto avalaría, pues, la posible hechura de Mora. De todos modos, las intervenciones posteriores que, percibimos ha sufrido la talla, tampoco ayudan a dictaminar un veredicto certero. La policromía que vemos es del siglo XVIII (Fig. 9).

Dicho esto, contemplamos la figura mariana colocada sobre una peana, apenas imperceptible, pues se presenta oculta por la nube de angelotes que se sitúan a los pies de la Virgen. En este sentido, este detalle tiene una enorme semejanza con la Inmaculada de José de Mora 
de la parroquial de los Santos Justo y Pastor. La disposición de los ángeles, los movimientos que desarrollan y su enorme parecido estilístico recuerdan las originales formas que este autor realizó en la colegiata jesuita. Asimismo, adorna la base la característica luna metálica, que creemos es de adición posterior.

Observamos a la Virgen erguida, adelantando ligeramente la pierna izquierda y dejando la opuesta en reposo. Une sus manos a la altura del pecho, aunque un tanto separadas del mismo. La posición de los brazos se desplaza sutilmente hacia la derecha. Se juntan las palmas de las manos por la base, separándose claramente del modelo canesco establecido. El mínimo movimiento de las extremidades es el único que se denota en la imagen. El rostro ovalado, de amplia frente, se perfila por las mejillas. Presenta boca pequeña de labios carnosos, nariz recta, ojos grandes almendrados y sutilmente inclinados, pestañas naturales y cejas arqueadas visiblemente destacadas. Su cabello castaño, largo y ondulado se dispone según el modo habitual, cubriendo hombros y cayendo sobre el pecho algún mechón. Su cabeza, mínimamente girada hacia la izquierda, se corona con la aureola de doce estrellas.

La figura mariana se atavía con túnica blanca, ricamente decorada con elementos geométricos y vegetales en oro, en los que se usa la técnica del picado de lustre. Se observan, igualmente, motivos florales en tonalidades rojizas y azuladas. Destacan principalmente las cenefas de las mangas y cuello. El manto azul, aunque esbozando las trazas de Alonso Cano, no acaba de respetar la forma ahusada tan característica del Racionero. La prenda se tercia por la cintura, dejando al descubierto el hombro derecho de la joven y cubriendo el contrario. El pico del paño cae con notoria voluminosidad sobre el brazo izquierdo. Por el borde de la vestimenta recorre una cenefa dorada, elaborando idénticos motivos decorativos que en la túnica. El forro del manto es de tonalidad rosácea. Los pliegues de las mangas, a golpes vivaces de la gubia, son muy propios del trabajo de Mora. Se aprecian menudos, abundantes y entrecortados. En cambio, en el manto, debido al volumen que se pretende proporcionarle, los plisados son mu- cho más redondeados y suaves, aunque marcadamente profundos por la cintura, dibujando líneas diagonales.

Finalmente, como anécdota curiosa, el P. Antonio de la Chica Benavides, en 1764, recoge en su Gazetilla curiosa una serie de referencias, entre piadosas y legendarias, acerca de esta talla, también llamada de la Buena Dicha:

En ella se venera [en la iglesia de San Pedro y San Pablo] una Imagen de nuestra Señora, hallada debaxo de tierra. Antes de su invencion, se descubrieron tres lapidas, que todas decian: Buena dicha: y debaxo de la tercera se hallo este Simulacro, que es muy milagroso, y fabricado con mucha destreza. Dieronla despues la forma de Concepcion, por orden de los Beneficiados de esta Parroquial.

Y un poco más adelante, cuenta que en el altar mayor de la iglesia había una imagen de la Concepción Inmaculada "de gallarda y perfecta Estatura, y tan milagrosa, que haviendose prendido fuego varias veces en esta Casa, ha sido prontamente libre, luego que se clamó por las Religiosas a esta Imagen".

La segunda de las imágenes que mencionábamos y que consideramos una atribución errónea es la Inmaculada del facistol catedralicio ${ }^{12}$. Según la atribución que Gallego y Burín hace, la Inmaculada del facistol que sustituyó a la Virgen de Belén, obra de Alonso Cano, en el remate de dicha estructura, sería hechura de Diego de Mora. Tal y como afirma, "la Virgencita que ocupa el tabernáculo, quizás hecha por Diego de Mora". A diferencia de la talla de la parroquial de San José, que previamente hemos analizado, ésta mantendría las trazas ahusadas características del modelo canesco (Fig. 10).

Ahora bien, si comparamos otras imágenes que se relacionan con la gubia de Diego de Mora con esta escultura, observamos notorias diferencias estilísticas. De este modo, la mencionada Inmaculada del templo albaicinero, la Virgen del Carmen, Ilamada por las religiosas como "La Gran Madre", de la iglesia del convento de Carmelitas Calzadas, la Virgen Sedente, denominada cariñosamente como "La Abadesa", del coro del convento del Santo Ángel Custodio, o la Inmaculada de la clausura del convento de 
Santo Tomás de Villanueva, mantienen una clara semejanza en las trazas del rostro. En todas ellas se perciben ciertas similitudes. Detalles como el cabello sensiblemente abultado a la altura de las mejillas, la cara ovalada, pequeña boca, nariz recta, hoyuelo en la barbilla, ojos almendrados, cejas notoriamente arqueadas, la cabeza levemente inclinada, marcando parecida pose, e incluso en la policromía, así lo confirmarían. Estas semejanzas tan evidentes entre las mencionadas esculturas, al compararlas con la talla del facis-

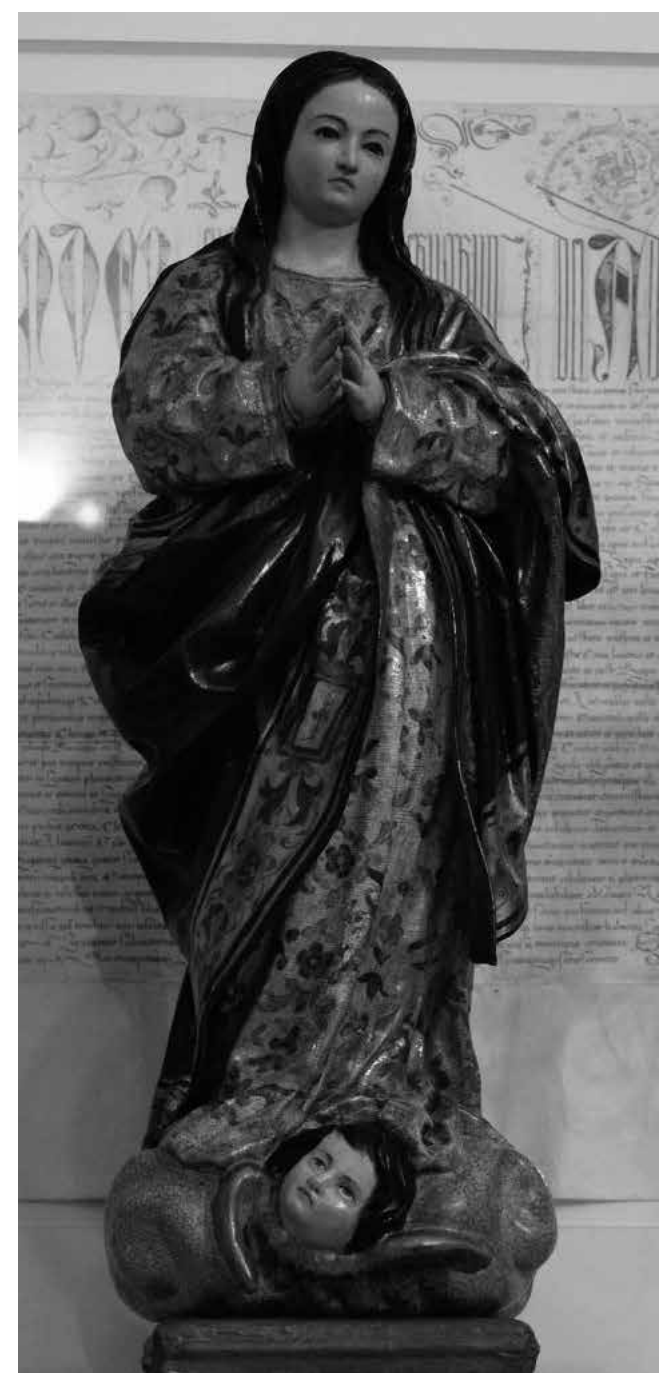

Fig. 10. Inmaculada. Catedral de Granada. Oratorio de Canónigos. Atribución dudosa a Diego de Mora, finales del siglo XVII o principios del siglo XVIII. tol, nos lleva a concluir que no se puede aseverar taxativamente que dicha imagen catedralicia haya salido de las manos de Diego de Mora. Más bien, estos datos nos hacen pensar lo contrario. ¿Podría tratarse de una imagen del taller de Pedro de Mena con policromía dieciochesca?

Dicho esto, pasaremos a describir someramente la imagen. La Virgen, sobre una peana, se contempla erguida, sobre el característico elemento nuboso, en el que se observa una cabeza alada de ángel, sensiblemente girada hacia la derecha. Llaman la atención las ausencias de la característica luna, tan habitual en las iconografías concepcionistas, así como de la serpiente, detalle muy habitual en las Inmaculadas del setecientos. Une sus manos a la altura del pecho, marcando pose triangular al tocar las yemas de los dedos. Éstas, aunque centradas, tienden sutilmente hacia la izquierda. Este movimiento se contrapone al que efectúa con la cabeza, justamente al lado opuesto. Su rostro se percibe más redondeado y menos afilado en los pómulos que como se observa en otros ejemplos. Sus ojos, aunque almendrados, no son tan rasgados. Asimismo, desaparece el hoyuelo de la barbilla. La disposición del cabello imita las formas del modelo de Cano, dejándolo caer sobre hombros y pecho. Finalmente, no adorna su testa con corona alguna. La Virgen se presenta ataviada con la correspondiente túnica blanca, en la que se aprecia la técnica de la estofa, sobre la que se ve la típica decoración chinesca del XVIII, a base de motivos vegetales y florales en tonos rojizos, amarillos, azulados y verdosos. Se cubre, igualmente, con el clásico manto azul, que se tercia por la cintura, dibujando la consabida forma ahusada, y dejando al descubierto el hombro derecho de la joven. El pico de la prenda cae sobre el brazo izquierdo. Por el borde del paño recorre un bello galón que, con elementos decorativos geométricos y vegetales, parece querer evocar motivos clasicistas. No es muy destacado el plegado de las vestimentas. Se limita al desarrollo de la dirección de las telas, esbozando trazas muy convencionales y suaves, incidiendo especialmente en la voluminosidad del manto.

Se puede apuntar que ejemplifica la tendencia a esencializar la representación de la Inmaculada al prescindir prácticamente de todos los atributos iconográficos. Ello da idea de lo arraigado del 
prototipo, perfectamente legible aun sin aquellos elementos expresivos que le daban sentido.

En reciente publicación, el prof. León Coloma identifica esta imagen con una que se cita en las Actas Capitulares bajo la advocación de Nuestra Señora del Patrocinio. Según este autor, sería donada por el racionero Juan Rico, con fecha de 8 de febrero de 1706. En este sentido, no compartimos esta opinión, puesto que una vez contrastado el dato, lo que en dicho documento aparece es que tal canónigo donó unas alhajas que tenía consignadas a Nuestra Señora del Patrocinio. No se especifica que donase la imagen en sí, ni da indicios de que fuese una talla de la Inmaculada, cuando lo lógico sería que se hubiese especificado la iconografía en cuestión, independientemente de que recibiese o no una advocación determinada.

Como conclusión a este trabajo, recogemos otros ejemplos de Inmaculadas que considera- mos salidas de las gubias de la saga de los Mora, siguiendo criterios meramente estilísticos, tras haber realizado un concienzudo trabajo de campo por el arzobispado de Granada. Según esto, incluiríamos en este muestrario otra Inmaculada de la iglesia parroquial de Cogollos Vega ${ }^{13}$, la de la iglesia del Convento del Santo Ángel Custodio ${ }^{14}$ y la del Museo de la Catedral de Granada ${ }^{15}$ (Figs. 11 y 12).

Así pues, tras haber hecho un recorrido por la iconografía inmaculista de esta familia de escultores, además de las imágenes que ya eran conocidas de su cuño, añadimos algunas nuevas en este artículo, proponiéndolas como pertenecientes a su obra artística. De este modo, en esta casuística estarían las Inmaculadas de Alhama de Granada, la de Albolote, las dos de Cogollos Vega, la de Güéjar Sierra, la de Pampaneira y la de la iglesia del Convento del Santo Ángel Custodio (Fig. 13).

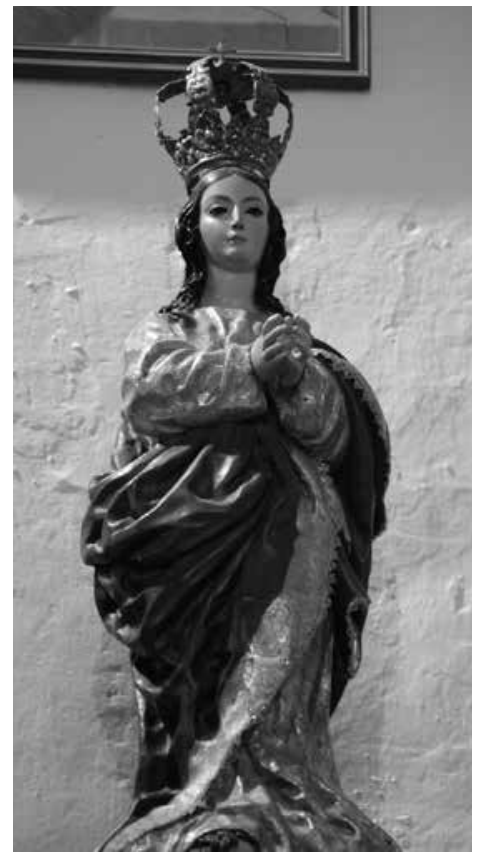

Fig. 11. Inmaculada de la iglesia parroquial de La Anunciación de Cogollos Vega (Granada). Círculo de los Mora, comienzos del siglo XVIII.

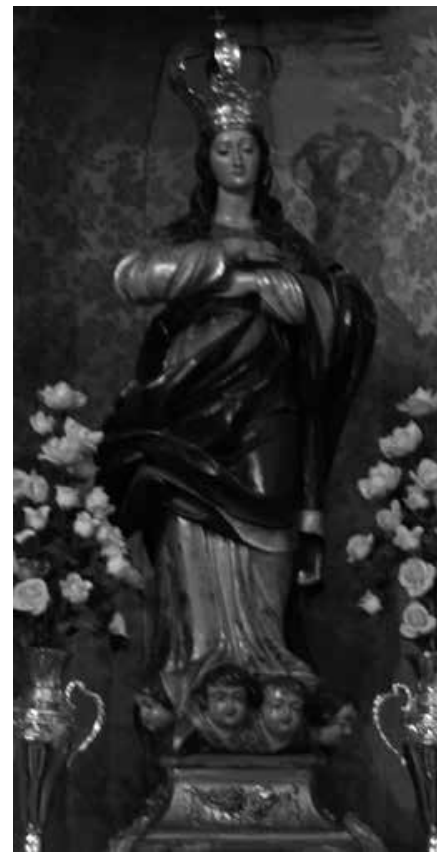

Fig. 12. Inmaculada de la iglesia del Convento del Santo Ángel Custodio (Granada). Círculo de los Mora, comienzos del siglo XVIII.

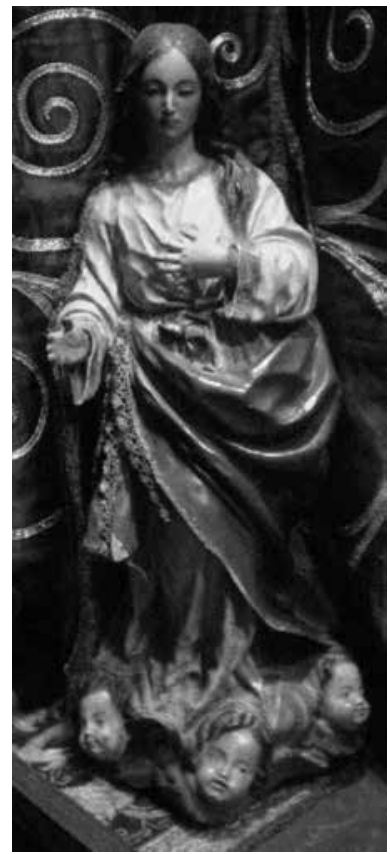

Fig. 13. Inmaculada del Museo de la Catedral de Granada. Círculo de los Mora, comienzos del siglo XVIII. 


\section{NOTAS}

${ }^{1}$ Sobre los aspectos biográficos de José de Mora, A. Gallego y Burín, José de Mora. Su vida y su obra, Universidad de Granada, Granada, 1988; J. J. López-Guadalupe Muñoz, José de Mora, Comares, Granada, 2000; A. J. Jaenada Jaenada, "José de Mora: memoria e imagen. I, pasado inmediato e infancia" Péndulo. Papeles de Bastitania, ${ }^{\circ}$ 10, 2009, pp. 273-304; A. J. Jaenada Jaenada, "Imagen de José de Mora: aproximación a una historia de su vida y obra. $2^{a}$ parte" Péndulo. Papeles de Bastitania, n 11, 2010, pp. 249-274. Sobre su extensa obra escultórica, la bibliografía es amplia y diseminada en función de la iconografía que trate o aspecto que pretenda reseñarse.

2 A. Gallego y Burín, José de Mora..., Op. Cit., pp. 136-138, M. Gómez-Moreno, "La Inmaculada en la escultura española" Miscelánea ComiIlas, XXIII, 1955, p. 391, Mª E. GómezMoreno, "Escultura del siglo XVII" en Ars Hispaniae. Historia Universal del Arte Hispánico (vol. XVI), Editorial Plus Ultra, Madrid, 1958, p. 261, D. Sánchez-Mesa Martín, "Aportaciones al estudio de la escultura religiosa en el Sacromonte" en La Abadía del Sacromonte. Exposición artístico-documental. Estudios sobre su significación y orígenes, Universidad de Granada, Granada, 1974, p. 56, A. Gallego y Burín, Granada. Guía artística e histórica de la ciudad, Edit. Don Quijote, Granada, 1982, p. 279, J. Hernández Díaz, "Escultura andaluza del siglo XVII" en Summa Artis (tomo XXVI), Espasa Calpe, Madrid, 1982, p. 202, D. SánchezMesa Martín, "El arte del Barroco: escultura, pintura, artes decorativas" en Historia del arte en Andalucía (vol. VII) (E. Pareja López, edic.), Editorial Gever, Sevilla, 1991, p. 242, Ma J. Martínez Justicia, La vida de la Virgen en la escultura granadina, Fundación Universitaria Española, Madrid, 1988, pp. 76-77, M $^{a}$ J. Martínez Justicia y D. Sánchez-Mesa Martín, "Inmaculada" en Pedro de Mena, 1628-1688, Junta de Andalucía. Consejería de Cultura, Cádiz, 1989, p. 138, T. Falcón Márquez, "Inmaculada" en La Inmaculada en el arte andaluz, Cajasur, Córdoba, 1999, pp. 56-58, J. J. López-Guadalupe Muñoz, José de Mora..., Op. Cit., p. 64, J. J. LópezGuadalupe Muñoz, "Inmaculada" en Alonso Cano. Arte e iconografía, Arzobispado de Granada, Granada, 2002, pp. 406-407, AA. VV., Guía artística de Granada y su provincia (vol. 1), Fundación José Manuel Lara, Sevilla, 2006, p. 140, M. A. León Coloma, "La Inmaculada Concepción en la escultura granadina" en A María no tocó el pecado primero. "La Inmaculada en Granada". Publicaciones Obra Social y Cultural Cajasur, Córdoba, 2005, p. 263 y J. A. Peinado Guzmán, Controversia teológica. Devoción popular. Expresión plástica. La Inmaculada Concepción en Granada, Universidad de Granada, Granada, 2011 [Tesis doctoral en el repositorio de la Universidad de Granada: http://0-hera.ugr.es.adrastea.ugr.es/ tesisugr/2009937x.pdf (consultado el 15-10-2013)], pp. 893-895.

${ }^{3}$ AA.VV., Guía artística de Granada y su provincia (vol. I)..., Op. Cit., p. 249.

${ }^{4}$ Archivo Histórico Diocesano de Granada (AHDGr), Leg. 255-F, Inventario de las imágenes y objetos pertenecientes a la Hermandad de la Purísima Concepción, pza. 34, s. f., AA. VV, Centenario de Alonso Cano en Granada. Catálogo, Caja de Ahorros de Granada, Granada, 1970, p. 93, J. Hernández Díaz, Op. Cit., p. 207, D. SánchezMesa Martín, "El arte del Barroco...", Op. Cit., pp. 234 y 268, Ma J. Martínez Justicia, Op. Cit., pp. 78-79, M. A. León Coloma, "La Inmaculada Concepción...", Op. Cit., p. 263, J. A. Peinado Guzmán, Op. Cit., pp. 902-904.

${ }^{5}$ AA. VV., Guía artística de Granada y su provincia (vol. II), Fundación José Manuel Lara, Sevilla, 2006, p. 378; J. A. Peinado Guzmán, Op. Cit., p. 905. p. 905 .

${ }^{6}$ J. A. Peinado Guzmán, Op. Cit.,

7 M. A. León Coloma, "La Inmaculada y los temas de pasión en la imaginería de los conventos agustino recoletos de Granada" en Granada. Tolle Lege, PP. Agustinos Recoletos. Provincia de Santo Tomás de Villanueva, Granada, 2009, pp. 193-197, J. J. Justicia Segovia, "Los conventos de Agustinas Recoletas. La Regla de San Agustín y las clausuras de Granada", en Granada. Tolle Lege..., Op. Cit., pp. 325, J. A. Peinado Guzmán, Op. Cit., pp. 910-912.

${ }^{8}$ L. Reau, Iconografía del arte cristiano. Iconografía de la Biblia. Nuevo Testamento (tomo 1, vol. 2), Ediciones del Serbal, Barcelona, 2000, p. 86.
9 J. A. Peinado Guzmán, Op. Cit., p. 913.

${ }^{10}$ A. de la Chica Benavides, Gazetilla curiosa, Convento de la Orden de la Stma. Trinidad Calzados, Granada, 1764, n 25 de junio, A. de la Chica Benavides, Gazetilla curiosa, Convento de la Orden de la Stma. Trinidad Calzados, Granada, 1764, n 10 de diciembre, A. Gallego y Burín, Granada. Guía artística..., Op. Cit., p. 352, Ma J. Martínez Justicia, Op. Cit., pp. 75-76, AA. W. Guía artística de Granada y su provincia (vol. I)..., Op. Cit., p. 236, J. A. Peinado Guzmán, Op. Cit., pp. 896-898.

${ }^{11}$ Giménez Serrano, Gallego y Burín en 1925, Hernández Díaz y Martínez Justicia la consideran de José de Mora: J. Giménez Serrano, Manual del artista y del viajero en Granada, Editorial Don Quijote, Granada, 1981, p. 353, A. Gallego y Burín, José de Mora..., Op. Cit., p. 135, J. Hernández Díaz, Op. Cit., p. 196. El mismo Gallego y Burín en su obra Granada. Guía artística e histórica de la ciudad y en la última Guía artística de Granada y su provincia, afirma que la autoría es de Pedro de Mena.

${ }_{12}$ Archivo de la Catedral de Granada (ACGr), Actas Capitulares, XXI: 8 de febrero de 1706, fol. 173 r., A. Gallego y Burín, Granada. Guía artística..., Op. Cit., p. 266, J. A. García García, Iconografía mariana en la catedral de Granada, Cabildo catedralicio, Granada, 1988, p. 90, Mª J. Martínez Justicia, Op. Cit., p. 79, P. López López, "Otros bienes muebles. El facistol y el candelero del cirio pascual" en $E /$ libro de la Catedral de Granada (vol. I), Cabildo Metropolitano de la Catedral de Granada, Granada, 2005, p. 715, AA.VV. Guía artística de Granada y su provincia (vol. I)..., Op. Cit., p. 29, M. A. León Coloma, "La escultura en la Catedral de Granada" en La Catedral de Granada. La Capilla Real y la iglesia del Sagrario (vol. I), Cabildo de la Santa Iglesia Catedral, Granada, 2007, p. 305, J. A. Peinado Guzmán, Op. Cit., pp. 906-909

13 J. A. Peinado Guzmán, Op. Cit., p. 914.

14 J. A. Peinado Guzmán, Op. Cit., p. 914.

${ }^{15}$ M. A. León Coloma, "La escultura en la Catedral de Granada...", Op. Cit., pp. 296-297, J. A. Peinado Guzmán, Op. Cit., p. 980 